\title{
Abdominal Abscess due to Perforation of the Terminal leum Caused by a Fish Bone Treated by the Conservative Treatment Using Antibiotics
}

\author{
Takayuki Sugimoto a, Mariko Hakoshima ${ }^{\text {a }}$, Hidetaka Hamasaki ${ }^{a}$, \\ Hidekatsu Yanai ${ }^{a}, \mathrm{~b}$
}

\begin{abstract}
Accidental ingestion of the foreign bodies rarely develops the perforation of gastrointestinal tract, and the perforation of gastrointestinal tract can lead to severe complications such as abscess, enteric fistula, or intestinal obstruction, and peritonitis. As the standard management for foreign body-induced bowel perforation, surgery is commonly selected. We experienced a patient whose abdominal abscess is due to perforation of the terminal ileum by a fish bone. Streptococcus intermedius was isolated from abdominal abscess. An absence of fistula between intestinal tract and abscess and a remarkable improvement of laboratory data and symptoms by using antibiotics made us select the conservative treatment. In conclusion, we succeeded to treat conservatively abdominal abscess due to perforation by a fish bone by using appropriately selected antibiotics.
\end{abstract}

Keywords: Abdominal abscess; Bowel perforation; Fish bone; Streptococcus intermedius

\section{Introduction}

The accidental ingestion of a fish bone can happen in everybody, and most of cases who ingested the foreign bodies such as a fish bone show no complication [1]. The possibility of development of perforation of gastrointestinal tract due to the foreign bodies is less than $1 \%$ [2]. The perforation of gastrointestinal tract can lead to severe complications such as the formation of abscess. The standard management for foreign body-induced bowel perforation is considered to be emergency surgery [3]. Here, we show a patient whose abdominal abscess due to perforation of the terminal ileum by a fish bone

Manuscript submitted September 8, 2017, accepted October 12, 2017

a Department of Internal Medicine, National Center for Global Health and Medicine, Kohonodai Hospital, Ichikawa, Japan

${ }^{\mathrm{b}}$ Corresponding Author: Hidekatsu Yanai, Department of Internal Medicine, National Center for Global Health and Medicine, Kohnodai Hospital, 1-7-1 Kohnodai, Ichikawa, Chiba 272-8516, Japan. Email: dyanai@hospk.ncgm. go.jp

doi: https://doi.org/10.14740/jmc2930e could be treated by the conservative treatment.

\section{Case Report}

A 64-year-old woman was admitted to our hospital due to fever and high level of C-reactive protein (CRP). She also has schizophrenia. Her body temperature was $38^{\circ} \mathrm{C}$. Physical examination revealed bulge, redness and tenderness of the right lower quadrant. Elevation of leukocyte counts $(10,500 / \mathrm{mL})$ and CRP $(8.02 \mathrm{mg} / \mathrm{dL})$ was observed. Abdominal computed tomography (CT) showed a large intra-abdominal abscess and extra-abdominal abscess (Fig. 1). Three slices of CT (crosssection) showed small round high-density area and coronal section CT showed linear high-density area (Fig. 2), suggesting the existence of a linear sharp foreign body. We asked the patient the possibility that she ingested a foreign body, and she remembered that she might ingest the bone of sea bream. We aspirated abscess and cultured the abscess content, and Streptococcus intermedius was isolated. We had started the treatment using tazobactam/piperacillin (TAZ/PIPC) $(18 \mathrm{mg} /$ day) empirically, and after the detection of Streptococcus intermedius, we changed the treatment from TAZ/PIPC to the combination of penicillin G (PCG) (18 million units) and clindamycin (CLDM) (2,400 mg/day) (Fig. 3). We considered the indication of operation, and the absence of fistula between intestinal tract and abscess and a remarkable improvement of CRP and symptoms by using antibiotics made us select the conservative treatment using antibiotics (Fig. 3). The abscess was successfully treated by antibiotics (Fig. 4), and almost disappeared on day 106.

\section{Discussion}

Accidental ingestion of the foreign bodies by young children is relatively common. In adults, rapid eating, poor vision, mental disorders, and drug intoxication or alcoholism may be risk factors for accidental ingestion of the foreign bodies [2]. Our patient has risk factors for accidental ingestion of the foreign bodies such as schizophrenia and rapid eating. The most common perforation site is the terminal ileum as our patient did, due to its narrow and angulating anatomical nature [4]. Fish bones are the most commonly observed objects that result in 

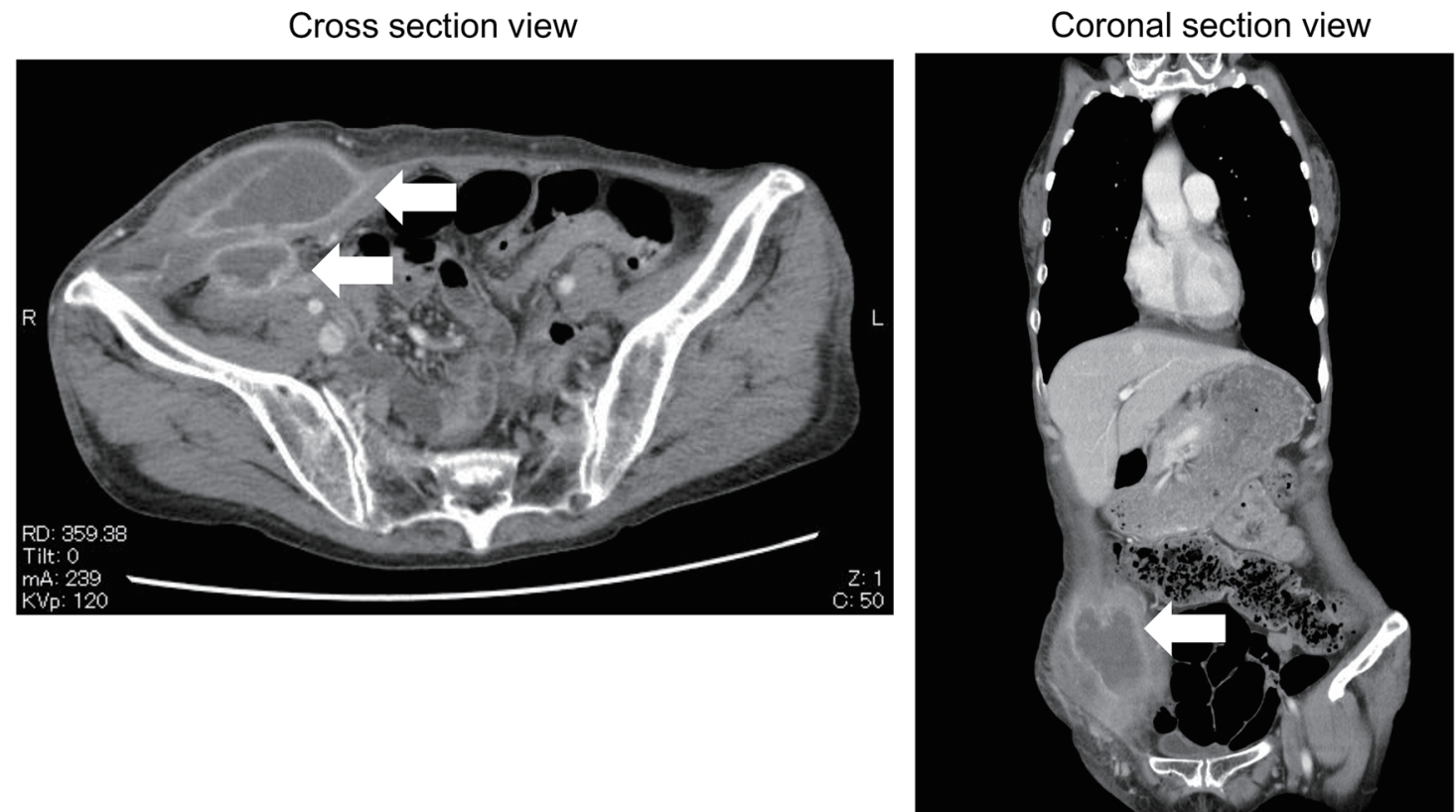

Figure 1. The enhanced abdominal computed tomography of abdominal abscess on admission.

\section{Cross section view}

\section{Coronal section view}
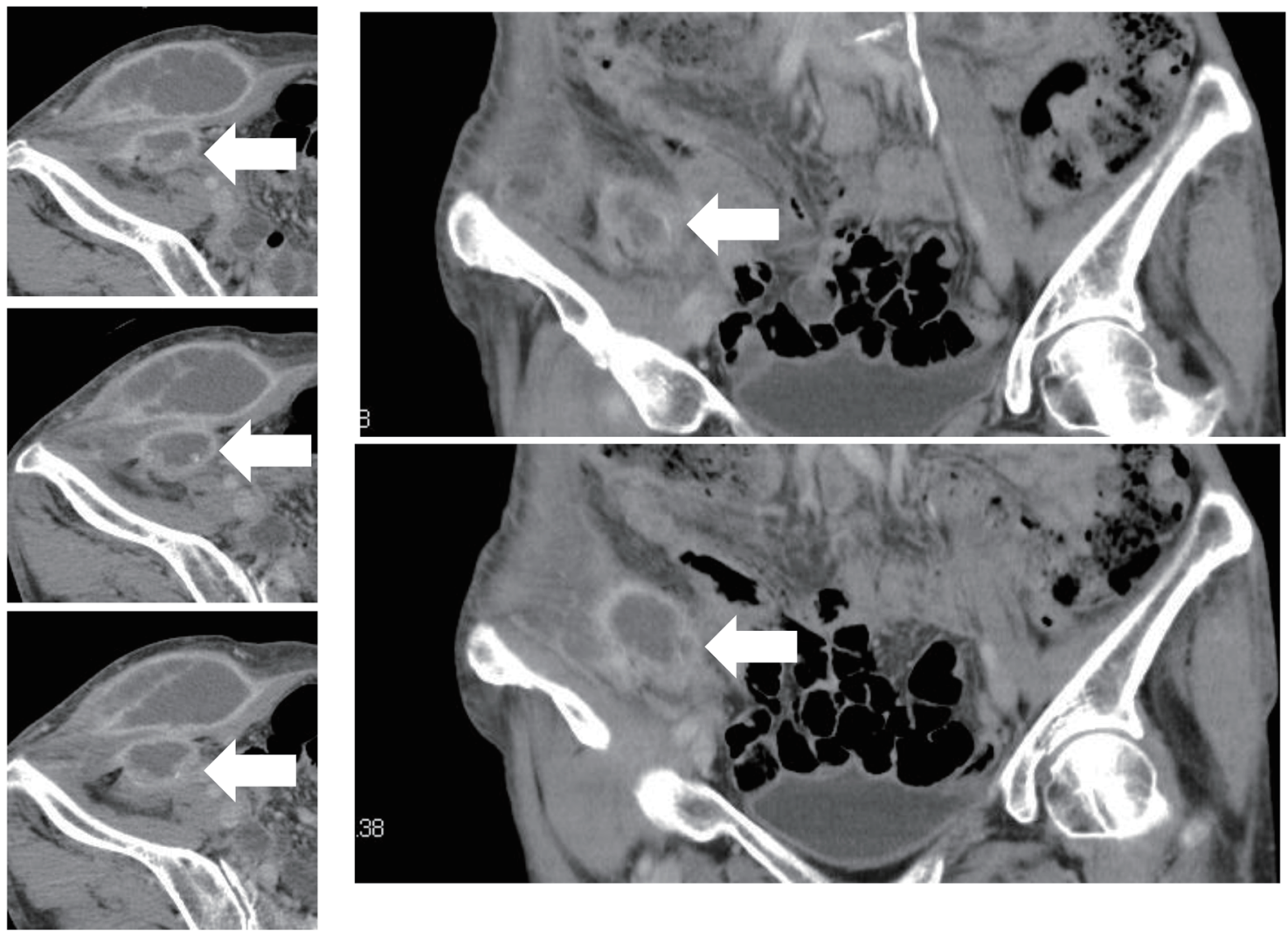

Figure 2. The enhanced abdominal computed tomography of a fish bone on admission. 


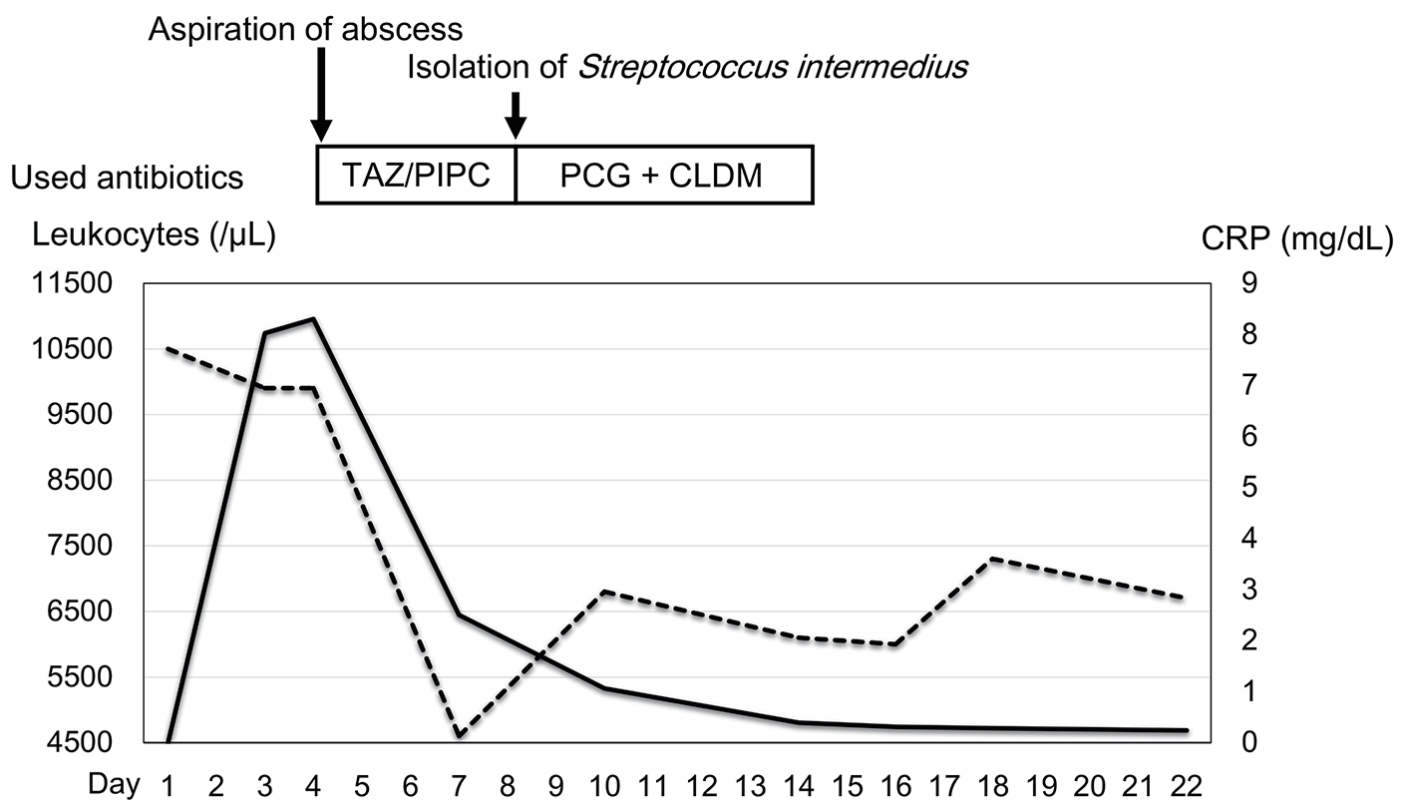

Figure 3. The treatment and changes in leukocyte counts and C-reactive protein (CRP) levels. Solid line and dotted line indicate CRP levels and leukocyte counts, respectively. CLDM: clindamycin; PCG: penicillin G; TAZ/PIP: tazobactam/piperacillin.

bowel perforation [5], which may result in the development of abscess, enteric fistula, or intestinal obstruction, and peritonitis. It is very difficult to make the diagnosis of bowel perforation due to the ingestion of fish bones [6], because fish bones are invisible on X-ray. As the modality to detect bowel perforation by fish bones, CT is useful like this case [7]. The standard treatment for bowel perforation due to the foreign bodies is emergency surgery [3]. In this case, the absence of fistula between intestinal tract and abscess and a remarkable improvement of CRP and symptoms by using antibiotics made us lead to the conservative treatment using antibiotics.

Streptococcus intermedius was detected from abdominal
Cross section view

Day 15

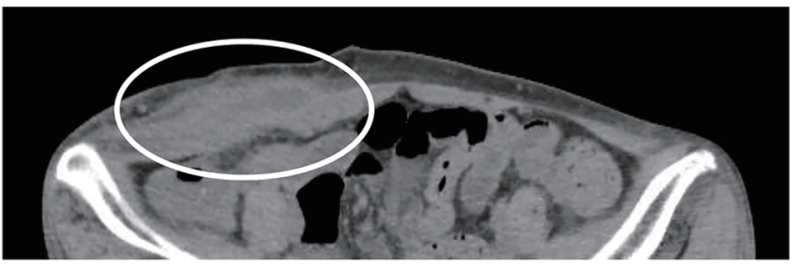

\section{Coronal section view}

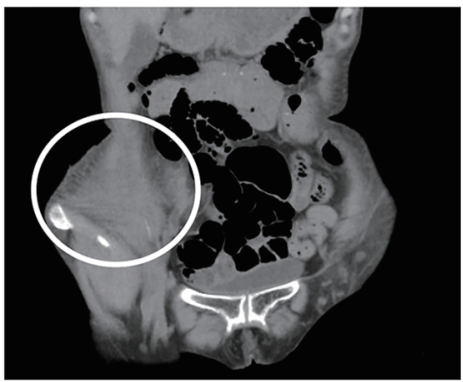

Day 106
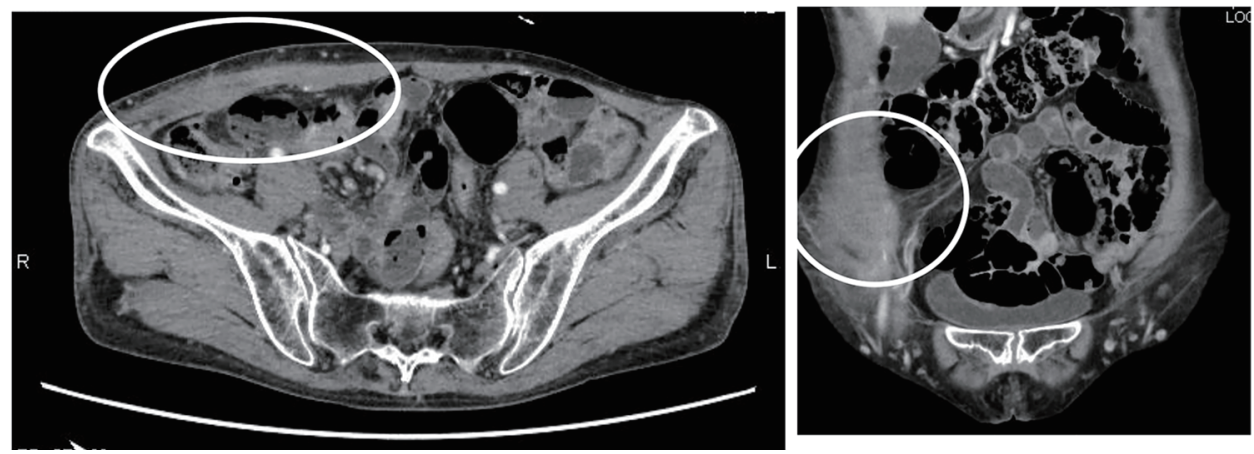

Figure 4. The enhanced abdominal computed tomography of abdominal abscess on day 15 and day 106. 
abscess of our patient. Streptococcus intermedius, a member of the Streptococcus anginosus group, is considered to be part of the normal microbial flora of the oral cavity [8], and rarely causes abdominal abscess. Aspiration of commensal oropharyngeal Streptococcus anginosus can lead to pneumonia, lung abscess, and pleural empyema [9-13]. Aspirated Streptococcus intermedius with a fish bone may induce abdominal abscess in this case.

In conclusion, we succeeded to treat conservatively abdominal abscess due to perforation by a fish bone by using appropriate antibiotics.

\section{Conflict of Interest}

All authors declare no conflict of interest.

\section{References}

1. Abel RM, Fischer JE, Hendren WH. Penetration of the alimentary tract by a foreign body with migration to the liver. Arch Surg. 1971;102(3):227-228.

2. Mapelli P, Head LH, Conner WE, Ferrante WE, Ray JE. Perforation of colon by ingested chicken bone diagnosed by colonoscope. Gastrointest Endosc. 1980;26(1):20-21.

3. Cho MK, Lee MS, Han HY, Woo SH. Fish bone migration to the urinary bladder after rectosigmoid colon perforation. World J Gastroenterol. 2014;20(22):7075-7078.

4. Singh RP, Gardner JA. Perforation of the sigmoid colon by swallowed chicken bone: case reports and review of literature. Int Surg. 1981;66(2):181-183.

5. Leijonmarck CE, Fenyo G, Raf L. Nontraumatic perforation of the small intestine. Acta Chir Scand. 1984;150(5):405-411.

6. Chiu JJ, Chen TL, Zhan YL. Perforation of the transverse colon by a fish bone: a case report. J Emerg Med. 2009;36(4):345-347.

7. Ngan JH, Fok PJ, Lai EC, Branicki FJ, Wong J. A prospective study on fish bone ingestion. Experience of 358 patients. Ann Surg. 1990;211(4):459-462.

8. Mirzanejad Y, Stratton CW. In: Mandell GL, Bennett JE, Dolin R, editor. Principles and practice of infectious diseases. Philadelphia: Elsevier Churchill Livingstone. Streptococcus anginosus Group; 2005. p. 2451-2455.

9. Molina JM, Leport C, Bure A, Wolff M, Michon C, Vilde JL. Clinical and bacterial features of infections caused by Streptococcus milleri. Scand J Infect Dis. 1991;23(6):659666.

10. Shinzato T, Saito A. The Streptococcus milleri group as a cause of pulmonary infections. Clin Infect Dis. 1995;21(Suppl 3):S238-243.

11. Wong CA, Donald F, Macfarlane JT. Streptococcus milleri pulmonary disease: a review and clinical description of 25 patients. Thorax. 1995;50(10):1093-1096.

12. Marinella MA, Harrington GD, Standiford TJ. Empyema necessitans due to Streptococcus milleri. Clin Infect Dis. 1996;23(1):203-204.

13. Porta G, Rodriguez-Carballeira M, Gomez L, Salavert M, Freixas N, Xercavins M, Garau J. Thoracic infection caused by Streptococcus milleri. Eur Respir J. 1998;12(2):357-362. 